\title{
Bulk metallic glasses: A new class of engineering materials
}

\author{
JOYSURYA BASU and S RANGANATHAN \\ Department of Metallurgy, Indian Institute of Science, Bangalore 560 012, India \\ e-mail: rangu@metalrg.iisc.ernet.in
}

\begin{abstract}
Bulk glass-forming alloys have emerged over the past fifteen years with attractive properties and technological promise. A number of alloy systems based on lanthanum, magnesium, zirconium, palladium, iron, cobalt and nickel have been discovered. Glass-forming ability depends on various factors like enthalpy of mixing, atomic size and multicomponent alloying. A number of processes is available to synthesise bulk metallic glasses. The crystallisation behaviour and mechanical properties of these alloys pose interesting scientific questions. Upon crystallisation many of these glasses transform to bulk nanocrystals and nanoquasicrystals. A detailed study of the structure and the crystallisation behaviour of glasses has enabled the elucidation of the possible atomic configuration in liquid alloys. Their crystallisation behaviour can be exploited to synthesise novel nanocomposite microstructures and their mechanical properties can be enhanced. A broad overview of the present status of the science and technology of bulk metallic glasses and their potential technological uses is presented.
\end{abstract}

Keywords. Bulk metallic glasses; glass-forming ability; fragility; nanocrystallisation; nanoquasicrystallisation; flow and fracture; soft magnetism; corrosion resistance.

\section{Introduction}

The first liquid alloy to be vitrified by cooling from the molten state was $\mathrm{Au}-\mathrm{Si}$ (Klement et al 1960). The cooling rate required to produce these glasses was of the order of $10^{6} \mathrm{Ks}^{-1}$, thereby restricting the specimen geometry to thin ribbons, foils and powders, where at least one dimension was small enough, of the order of microns, to permit such a high cooling rate. During the three decades following this seminal discovery a number of alloy systems, including iron-based alloys, were found amenable to glass formation. The principal uses of metallic glasses were derived from their increased corrosion resistance, wear resistance and reduced eddy current losses in ferromagnetic ribbons as compared to the crystalline alloys of identical compositions (Anantharaman 1984).

The promising attributes of metallic glasses have led metallurgists to dream of new alloys that would form glasses at low cooling rates like oxide glasses, which would enable their production in bulk form. This dream was turned into a reality by the pioneering investigations of Inoue starting from 1988 (Inoue et al 1988). The contributions from his group at Sendai, Japan, documented in a large number of papers in the literature, cover a wide variety of 
multicomponent alloys, deal with practically all aspects of glass science and dominate the field. Several significant contributions have come from Johnson's group at Caltech, USA (Johnson 1999), where the pioneering investigations of Duwez gave birth to the field of metallic glasses (Klement et al 1960). While the initial alloys were based on lanthanides, there was a gradual expansion in the elemental basis such that today more than a dozen different metals form the basis for bulk metallic glasses (BMG). They offer for the first time the possibility of the study of the properties of the glassy and the supercooled liquid states on a temporal and spatial scale previously considered unattainable. A totally unexpected result was that on devitrification they produced nanocrystals, paving the way for bulk nanostructured materials. Some of them gave rise to quasicrystals, again leading to bulk nanoquasicrystalline materials. It also indicated a link with icosahedral order for at least some of these glasses. Current interest in this subject is captured in a series of books (Inoue 1998, 1999), reviews (Inoue 2000; Johnson 1999, 2002) and several conference proceedings (Johnson et al 1999; Inoue et al 2001; Egami et al 2003).

\section{Glass-forming ability}

Amorphisation of an alloy from the liquid state essentially involves the kinetic suppression of nucleation and growth from an undercooled melt. The determination of a glass transition temperature in rapidly quenched $\mathrm{Au}-\mathrm{Si}-\mathrm{Ge}$ established firmly that they are true glasses (Chen $\&$ Turnbull 1967). A differential scanning calorimetry trace of a glass (figure 1) brings out three important temperature-defined transitions, namely the melting point $\left(T_{m}\right)$, the glass transition temperature $\left(T_{g}\right)$ and the crystallisation temperature $\left(T_{x}\right)$. There is considerable interest in devising criteria for forming glasses based on these temperatures. Two of them in particular have found widespread use. Turnbull (1969) pointed to the importance of the reduced glass temperature $T_{r g}$ as the ratio between the glass transition temperature $\left(T_{g}\right)$ and the liquidus temperature $\left(T_{m}\right)$, of an alloy. As the reduced glass transition temperature increases from 0.5 to $0 \cdot 66$, the required cooling rate for glass formation decreases, making it possible to synthesise thicker glasses at slower cooling rates. Recent investigations have shown even higher values of $\sim 0.71$ in some systems. Another parameter $\Delta T_{x}$, the temperature interval between $T_{g}$

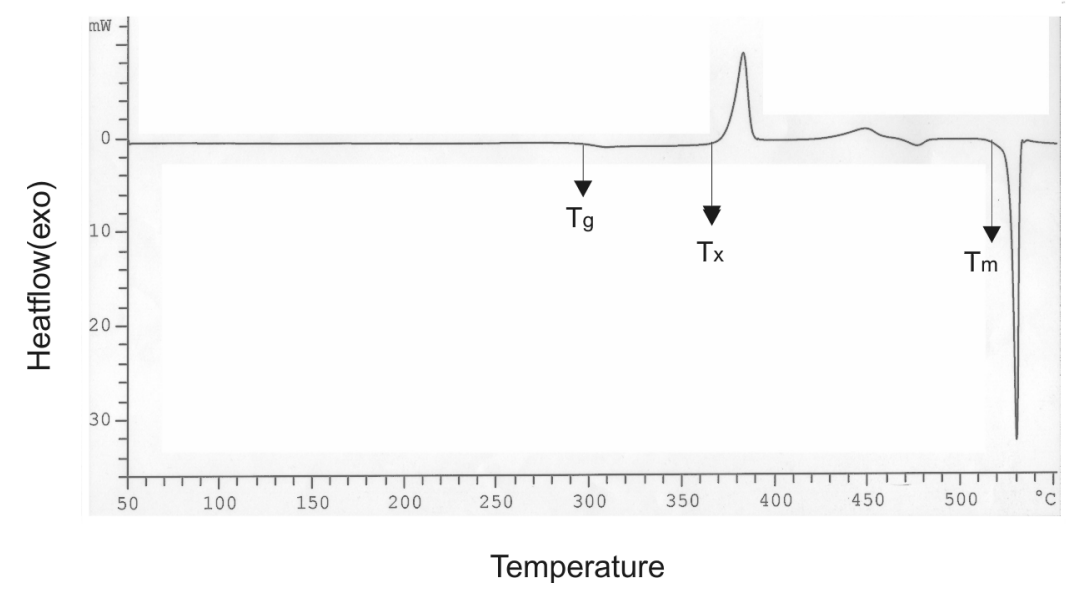

Figure 1. DSC thermogram of $\mathrm{Pd}-\mathrm{Cu}-\mathrm{Ni}-\mathrm{P}$ bulk metallic glass. 

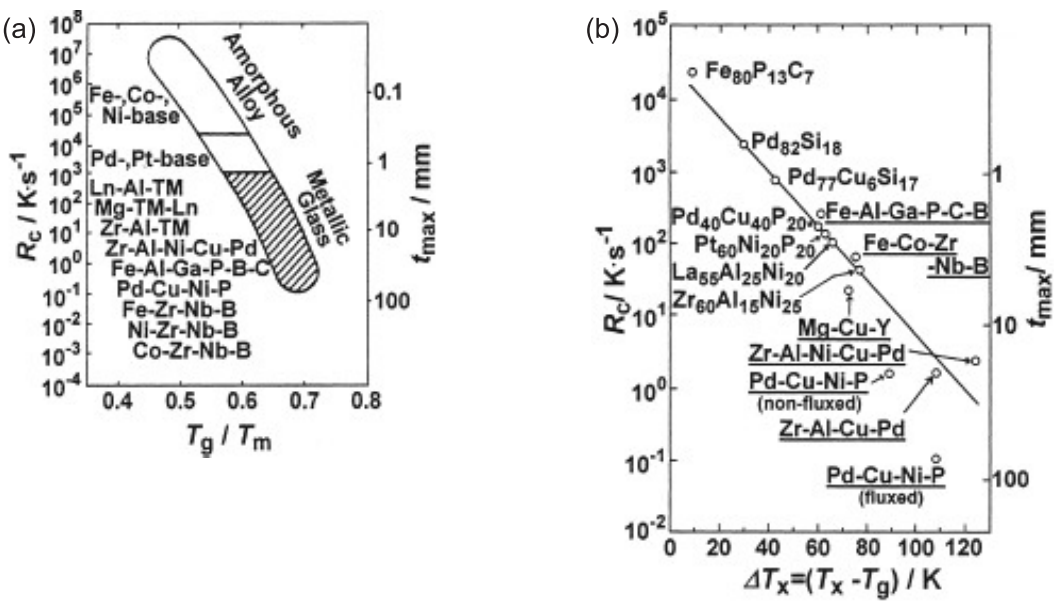

Figure 2. Correlation in different glass-forming alloys between (a) critical cooling rate $\left(R_{c}\right)$, reduced glass transition temperature $\left(T_{g} / T_{m}\right)$ and thickness of glass $\left(t_{\max }\right)$, (b) critical cooling rate $\left(R_{c}\right)$, supercooled liquid region $\left(T_{x}-T_{g}\right)$ and thickness of glass $\left(t_{\max }\right)$. (Inoue 2000.)

and $T_{x}$ has been emphasised by Inoue (2000). This denotes the accessible supercooled liquid region and the larger it is, the greater is the glass-forming ability (GFA). Both high $T_{r g}$ and $\Delta T_{x}$ correlate with cooling rate and thickness (figure 2). Figure 3 is a schematic representation of the requirement of cooling rates for different types of glass formation. It is seen that the cooling rates span several orders of magnitude from $10^{6} \mathrm{Ks}^{-1}$ to $0 \cdot 1 \mathrm{Ks}^{-1}$.

The development of a predictive model that identifies the alloy families and the composition ranges that would form bulk glasses remains a grand scientific challenge. Currently, alloy discovery progresses by empiricism. The three major contributing factors to glass formation are atomic size mismatch, high negative heat of mixing, and multicomponent alloy system. These are the most widely accepted empirical rules for the formation of glasses as enunciated by Inoue (1995). While the first two criteria were appreciated from the beginning of the study of metallic glasses, the need for multicomponents has been recognised as being of great importance only after the advent of BMG and is often termed as the confusion principle in glass formation. The rationale behind this principle rests on the following arguments. An exploration into the crystal structures of compounds and solid solution phases reveals that as the order of a structure goes from elemental to binary, ternary and higher order, the number of new structure types diminishes. Thus for crystal nucleation to occur in the melt of a multicomponent system, long range diffusion is necessary. The introduction of a new

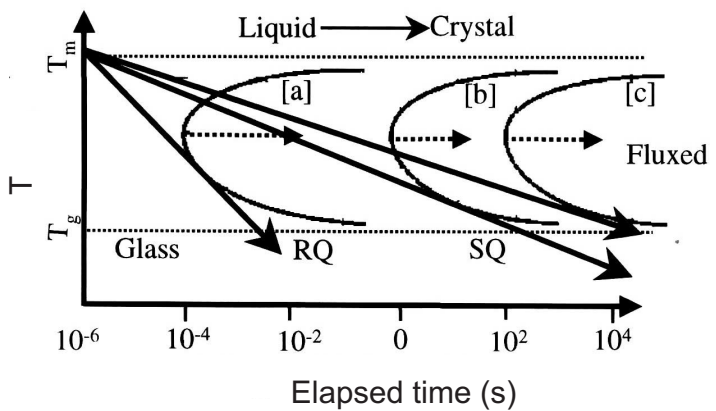

Figure 3. Continuous cooling transformation diagram of several glass-forming alloys with superimposed critical cooling rates: (a) metallic glasses, (b) bulk metallic glasses, (c) fluxed bulk metallic glasses (after Johnson 1999). 
component into an alloy also introduces local atomic level strain along with chemical disorder, frustrating crystallisation. For two atoms of differing sizes, there exists a critical maximum solubility in both the terminal solid solutions. Outside these critical concentrations, the solid solutions become topologically unstable with respect to transformation to the glassy phase. Multicomponent glass-forming alloys contain elements with significant differences in their atomic sizes. Due to this, the random packing density of the alloy increases. Ramachandra Rao (1980) has postulated that an alloy with the smallest possible molar volume is most prone to glass formation. Egami (2002) has extended his earlier work on the topological criterion to local structural instability. He has proposed that multicomponent alloys may experience a wide distribution in local glass transition temperatures.

While it is clear that the search for bulk metallic glasses has to be carried out in higher order phase diagrams - the advent of BMGs has certainly breathed fresh life into theoretical and experimental phase diagram determinations - the available experimental data are scarce. Thus only $5 \%$ of $\sim 170,000$ ternary and $<1 \%$ of possible nearly four million quaternary diagrams have been investigated so far. In binary alloys, a low-lying eutectic signifies the stabilization of the liquid. It is expected that higher order eutectics with low melting points may be good glassforming compositions. It appears that a quaternary eutectic in $\mathrm{Pd}-\mathrm{Cu}-\mathrm{Ni}-\mathrm{P}$ and a quinary eutectic in $\mathrm{Zr}-\mathrm{Ti}-\mathrm{Cu}-\mathrm{Ni}-\mathrm{Be}$ are regions favourable for glass formation. It is this absence of experimental data that forces one to take recourse to semi-empirical rules formulated by Inoue (1995). It is to be hoped that the concept of Mendeleev number introduced by Pettifor (1988) may be of value in looking for crystal structure types and regions for glass formation at such compositions.

\section{Glass-forming systems}

Glass-forming systems can be classified in several ways, ferrous and nonferrous alloys, metalmetal and metal-metalloid glasses, based on constituent elements and so on. Table 1 gives an illustrative list of a few important bulk glass-forming alloys arranged on the elemental basis. They are arranged in decreasing atomic size of the basic element ( $\left.\mathrm{Ln}-, \mathrm{Zr}_{-}, \mathrm{Mg}-, \mathrm{Pd}-, \mathrm{Fe}-\right)$, as size seems to play a predominant role in glass formation.

For the lanthanides, alloying with an LTM and $\mathrm{Al}$ (Ln-LTM-Al, Ga) leads to excellent glass-forming ability (GFA). While the first composition to be reported was La55-Al25-Ni20 (Inoue et al 1989), the addition of $\mathrm{Cu}$ and $\mathrm{Co}$ led to La55-Al25-Cu10-Ni5-Co5 glass with $9 \mathrm{~mm}$ dimensions, $98 \mathrm{~K}$ as $\Delta T_{x}$ and a $T_{r g}$ of 0.70 (Inoue et al 1993).

Zirconium alloys are one of the most widely studied glass-forming systems. $\mathrm{Ti}, \mathrm{Zr}$ and $\mathrm{Hf}$ are in the same group in the periodic table. Zr, Hf and Ti are early transition metals. They can be alloyed with late transition metals such as $\mathrm{Ni}$ and $\mathrm{Cu}$ (Inoue et al 1990). If $\mathrm{Al}$ is added as well. the glass-forming ability increases in this class (ETM-LTM-Al, Ga). Spectacular improvement occurs with the addition of Be, a very small size atom (Peker \& Johnson 1993). Though $\mathrm{Cu}$-base glasses have been reported, their basic composition places them in the $\mathrm{Zr}$ category.

$\mathrm{Mg}-\mathrm{Ln}-\mathrm{LTM}$ forms another class. Mg65-Y10-Cu25 is particularly noted for its high GFA (Inoue et al 1992). Amiya \& Inoue (2000) showed that additional alloying with Mg65-Y10Cu5-Ag5-Pd5 leads to further increase in $T_{r g}$.

Pd-TM-metalloid forms another important class (TM - transition metal). In a classic and early experiment, Drehman et al (1982) showed that it is possible to produce glasses of $5 \mathrm{~mm}$ thickness in Pd40-Ni-40-P20. If one centimetre can be called bulk, the first report of a BMG was that of Kui et al (1984) on fluxed Pd40-Ni40-P20 to produce a bulk glass. The import of this paper was not felt at that time, in the way the discovery in the same 
Table 1. Illustrative list of bulk metallic glasses with critical parameters and references. Values are indicative.

\begin{tabular}{|c|c|c|c|c|c|c|c|c|}
\hline Base & $\begin{array}{l}\text { Radius } \\
(\AA)\end{array}$ & Alloy system & Alloys & $\Delta T_{x}$ & $T_{r g}$ & $\begin{array}{c}t \\
(\mathrm{~mm})\end{array}$ & $\begin{array}{c}R c \\
(\mathrm{~K} / \mathrm{s})\end{array}$ & Reference \\
\hline \multicolumn{9}{|c|}{ Metal-metal } \\
\hline $\mathrm{La}$ & $2 \cdot 74$ & Ln-Al-LTM & $\begin{array}{c}\mathrm{La}_{55}-\mathrm{Al}_{25}-\mathrm{Ni}_{20} \\
\mathrm{La}_{55}-\mathrm{Al}_{25}-\mathrm{Ni}_{5}-\mathrm{Cu}_{10}-\mathrm{Co}_{5}\end{array}$ & $\begin{array}{l}69 \\
98\end{array}$ & $\begin{array}{l}0 \cdot 68 \\
0 \cdot 70\end{array}$ & $\begin{array}{l}7 \\
9\end{array}$ & 100 & $\begin{array}{l}\text { Inoue et al } \\
(1989,1990)\end{array}$ \\
\hline $\mathrm{Zr}$ & $2 \cdot 16$ & $\begin{array}{c}\mathrm{Zr}-\mathrm{Al}-\mathrm{TM} \\
\mathrm{Zr}-\mathrm{Ti}-\mathrm{TM}-\mathrm{Be}\end{array}$ & $\begin{array}{c}\mathrm{Zr}_{60}-\mathrm{Al}_{20}-\mathrm{Ni}_{20} \\
\mathrm{Zr}_{41 \cdot 2}-\mathrm{Ti}_{13 \cdot 8}-\mathrm{Cu}_{12 \cdot 5}-\mathrm{Ni}_{10}- \\
\mathrm{Be}_{22 \cdot 5}\end{array}$ & $\begin{array}{l}77 \\
25\end{array}$ & $\begin{array}{l}0 \cdot 64 \\
1-10\end{array}$ & 30 & $1-10$ & $\begin{array}{l}\text { Inoue et al } \\
(1990), \\
\text { Johnson \& } \\
\text { Peker (1993) }\end{array}$ \\
\hline Metal & -metall & Mg-Ln-LTM & $\begin{array}{c}\mathrm{Mg}_{65}-\mathrm{Y}_{10}-\mathrm{Cu}_{25} \\
\mathrm{Mg}_{65}-\mathrm{Y}_{10}-\mathrm{Cu}_{5}-\mathrm{Ag}_{5}-\mathrm{Pd}_{5}\end{array}$ & $\begin{array}{l}70 \\
35\end{array}$ & $\begin{array}{l}0.59 \\
0.62\end{array}$ & 7 & 200 & $\begin{array}{l}\text { Inoue et al } \\
(1992) \\
\text { Amiya \& } \\
\text { Inoue (2000) }\end{array}$ \\
\hline \multirow[t]{2}{*}{$\mathrm{Pd}$} & 1.79 & Pd-LTM-P & $\mathrm{Pd}_{40}-\mathrm{Ni}_{40}-\mathrm{P}_{20}$ & 50 & & & $1 \cdot 28$ & $\begin{array}{l}\text { Drehman } \\
\text { et al }(1982)\end{array}$ \\
\hline & & & $\begin{array}{c}\mathrm{Pd}_{40}-\mathrm{Cu}_{30}-\mathrm{Ni}_{10}-\mathrm{P}_{20} \\
\text { Fluxed } \\
\mathrm{Pd}_{42 \cdot 5}-\mathrm{Cu}_{30}-\mathrm{Ni}_{7 \cdot 5}-\mathrm{P}_{20}\end{array}$ & 95 & $0 \cdot 71$ & $\begin{array}{l}40 \\
72\end{array}$ & $\begin{array}{c}1 \cdot 57 \\
0 \cdot 1 \\
0 \cdot 067\end{array}$ & $\begin{array}{l}\text { Inoue et al } \\
(1996) \\
\text { Inoue et al } \\
(1997) \\
\text { Nishiyama } \\
\text { \& Inoue } \\
(2002)\end{array}$ \\
\hline $\mathrm{Fe}$ & $1 \cdot 72$ & $\begin{array}{c}\mathrm{Fe}-(\mathrm{Al}, \mathrm{Ga})- \\
\text { (metalloid) } \\
\mathrm{Fe}-\mathrm{TM}-\mathrm{B}\end{array}$ & $\mathrm{Fe}_{72}-\mathrm{A}_{15}-\mathrm{P}_{11} \mathrm{C}_{5} \mathrm{~B}_{4} \mathrm{Ge}_{2}$ & 60 & & 2 & 10 & $\begin{array}{l}\text { Inoue et al } \\
(1995,1996)\end{array}$ \\
\hline
\end{tabular}

year of a quasicrystalline state in rapidly quenched Al-Mn alloys by Shechtman et al (1984) led to explosion in research. Recent work has also established a subtle connection between some BMGs and quasicrystals. Inoue et al (1996) showed that partial replacement of $\mathrm{Ni}$ by $\mathrm{Cu}$ leading to $\mathrm{Pd} 40-\mathrm{Cu} 30-\mathrm{Ni10-P20}$ leads to glass dimensions with $40 \mathrm{~mm}$ diameter and cooling rate of $1.57 \mathrm{~K} / \mathrm{s}$. Fluxing led to a still smaller cooling rate (Inoue et al 1997). The alloy crystallised with one peak, indicating proximity to an eutectic composition. Nishiyama \& Inoue (2002) have fine-tuned the composition further so that the alloy corresponding to the exact quaternary eutectic can be solidified at the slowest possible rate.

In the case of Fe-base glasses two varieties can be discerned. The combination with $\mathrm{Al}, \mathrm{Ga}$ and a metalloid forms one possibility and the other with ETM (Zr, Hf) and the metalloid B (Inoue et al 1995). While ferrous glassy ribbons were mainly developed for their magnetic properties, iron based BMGs are also driven by nonferromagnetic structural applications. This is the second variety typified by $\mathrm{Fe}-\mathrm{Al}$-metalloid. A recipe similar to that for iron works well for Co- and Ni-based glasses as well.

The absence of Al-based BMGs in this list is conspicuous, even though it figures as an important alloying element in several BMGs. It is interesting to note that it is the search for Al-based metallic glasses that led to the discovery of BMGs. Indian researchers played an important role in the early seventies, when they showed that Al-Ge (Ramachandra Rao et al 
1972), Al-Ni (Chattopadhyay et al 1976) and Al-Pd (Sastry et al 1978) alloys formed glasses but this was not pursued further. Inoue et al (1988) took up these systems and discovered that the addition of lanthanide elements gave excellent glasses, a conclusion independently arrived at by He et al (1988). It was sheer genius that Inoue saw the value of the wide supercooled region in higher lanthanide compositions and went on to produce Ln-based BMGs. Even though $\mathrm{Al}$ alloys are marginal glass-formers, it has spawned a rich field as on devitrification they give rise to nanocrystals with vastly improved mechanical properties (Perpezeko \& Hebert 2002).

\section{Synthesis}

Bulk metallic glasses can be synthesised either by solidification or by solid state processing, a drastic change from the rapid solidification techniques previously employed for synthesis. The oldest of all the techniques in solidification route is water-quenching. In this method the alloy is melted in a vacuum-sealed quartz tube and is then water-quenched. Cooling rate available in this technique generally varies in the range of $10-100 \mathrm{Ks}^{-1}$. Modern techniques of preparing bulk metallic glasses involve unidirectional zone melting, arc melting and then injection moulding or suction casting in a copper mould. This process has got many variants. The melt can be electromagnetically levitated and then cast into copper mould.

Fluxing during solidification has already been referred to. It removes heterogeneous impurities and allows for glass formation. Its use in Pd alloys has been reported by Drehman et al (1982) and Inoue et al (1997). One of the Fe-based glasses that attracted considerable interest in the past is Fe40-Ni40-P14-B6 (Ranganathan \& von Heimendahl 1981; Tiwari et al 1987), when it was produced as melt spun ribbons of 50 microns in thickness. Shen \& Schwarz (2001) have employed flux-melting and water-quenching to produce bulk glasses in the form of $1 \mathrm{~mm}$ rods.

Amorphisation of different alloy systems by mechanical milling has been reported by Murty \& Ranganathan (1998). Mechanical alloying does not involve any melting for amorphisation. This process also has a number of controlling paramaters, e.g milling energy, milling speed, ball to powder ratio, milling atmosphere etc. $\mathrm{Zr}-\mathrm{Cu}-\mathrm{Ni}-\mathrm{Al}$ and $\mathrm{Zr}-\mathrm{Cu}-\mathrm{Ni}-$ Al-Ti bulk glass-forming compositions have been mechanically milled and have been found to produce an amorphous phase (Madge 1999). Microstructural evolution with progress of milling has been monitored. Figure 4 shows the optical micrograph of $\mathrm{Zr}-\mathrm{Cu}-\mathrm{Ni}-\mathrm{Al}-\mathrm{Ti}$ mechanically milled powders at the initial stages. Elemental layers are produced at the initial stages of milling, thickness of which decreases with the progress of time and ultimately amorphises.

Conner et al (1998) have reported the synthesis of bulk metallic glass composites by introducing tungsten, steel and silicon carbide fiber or particles into amorphous matrix. The reinforcements do not act as heterogeneous nucleation sites and mechanical properties of the composite are better than those of the bulk glass.

\section{Structure}

Ideally amorphous alloys are characterised by the presence of a hump in the X-ray diffraction pattern. From such patterns it is possible to derive partial distribution functions and gather information about atomic coordination environments. Unlike silicate glasses there is no description based on random networks. Instead the model that has found most favour in 


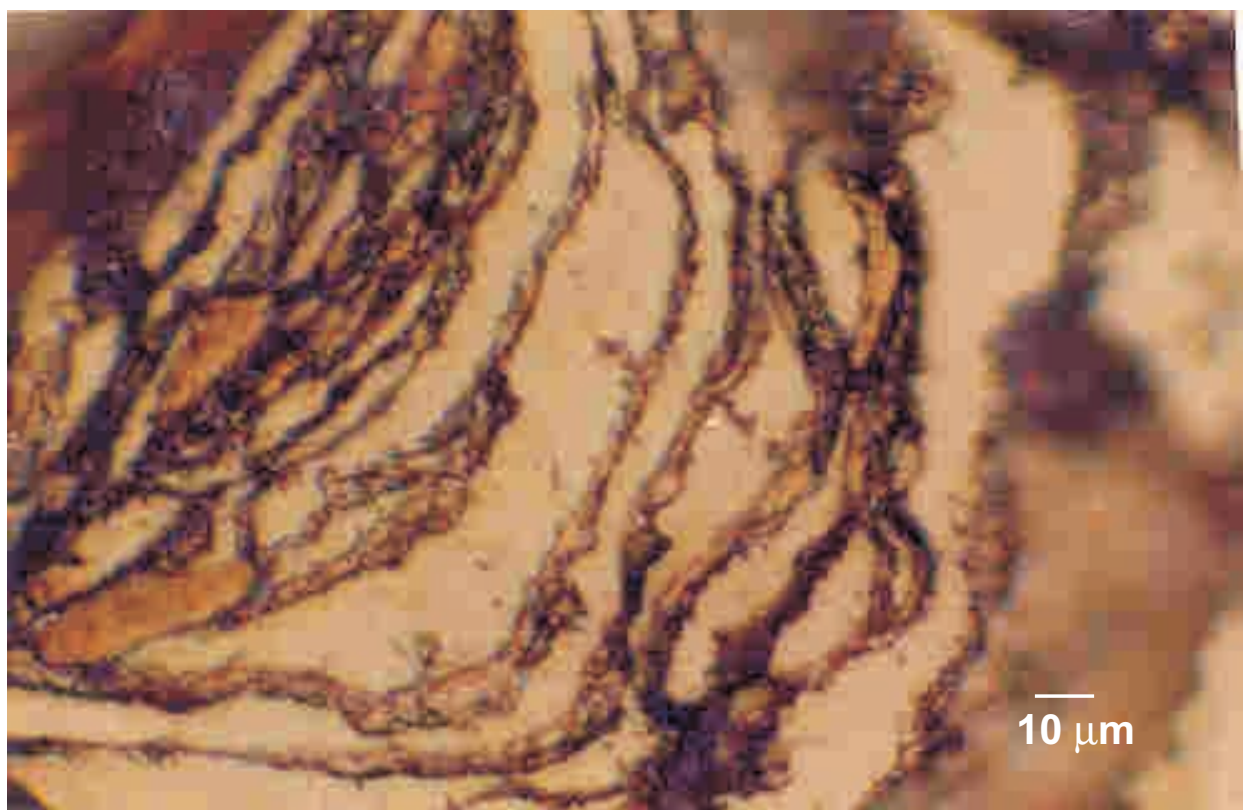

Figure 4. Optical micrograph of mechanically alloyed $\mathrm{Zr}-\mathrm{Cu}-\mathrm{Ni}-\mathrm{Al}-\mathrm{Ti}$ powder showing the formation of elemental layers at the early hours of milling (Madge 1999).

describing the metallic glass structure is known as the polytetrahedral structure. As tertahedra cannot pack space, inevitably other configurations arise. These have been termed Bernal deltahedra (figure 5). In some of these, voids are present, which can be filled by metalloid
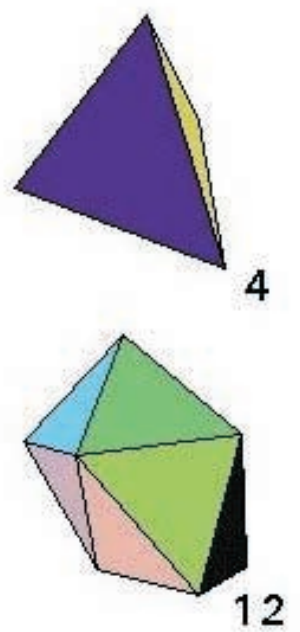

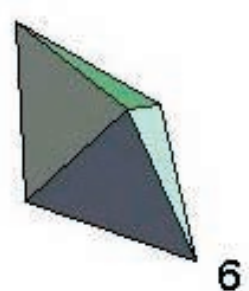

6

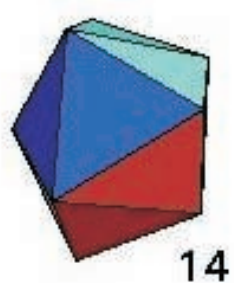

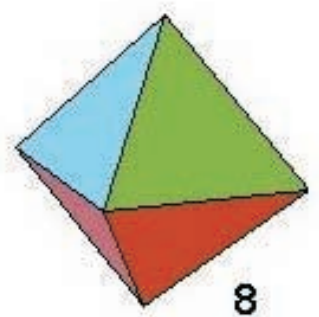

8

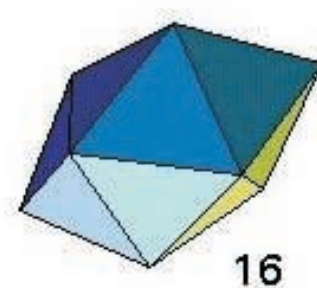

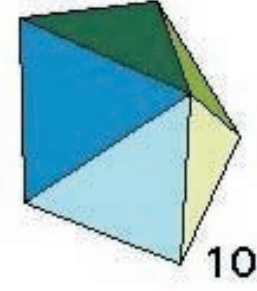

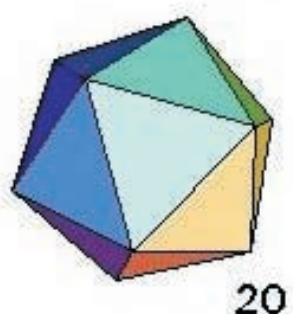

Figure 5. The eight Bernal convex deltahedra. 
atoms. It is also noteworthy that the icosahedron is one of the possible deltahedra. The crystallisation. of some glasses leads to quasicrystals, indicative of the icosahedral order in the glass structure as well ( $\mathrm{Li}$ et al 2001). It has been shown that icosahedral clusters are present in the $\mathrm{Zr}-\mathrm{Pd}$ amorphous alloy with zirconium atom at the centre of the cluster.

\section{Crystallisation}

As glasses are metastable, they devitrify upon heating. Crystallisation reactions have been broadly classified (Herold \& Koster 1978) into three categories; namely polymorphous, primary and eutectic crystallisation. In primary crystallisation, a crystal different in composition from that of the matrix precipitates out, but in polymorphous crystallisation a precipitate of the same composition as that of the matrix precipitates out. In eutectic crystallisation, the glassy matrix separates into two crystalline phases according to the eutectic reaction. Eutectic crystallisation and its dependence on annealing temperatures have been studied in $\mathrm{Fe}-\mathrm{Ni}-\mathrm{P}-\mathrm{B}$ amorphous alloys (Tiwari et al 1987). Interlamellar spacing increases with the lowering of temperature below the glass-transition temperature but this behaviour is reversed above the glass-transition temperature. Banerjee et al (2001) have reported nucleation and growth behaviour in zirconium-based metallic glasses and the different microstructures which can be produced in the alloy systems.

A noteworthy feature is that several BMGs give rise to nanocrystals. This can arise due to phase separation in the liquid or glass (Busch et al 1995). Such a fine-scale separation preceding crystallisation determines the scale of crystallisation to be nanometric. Loffler et al (2000) have used SANS, atom probe and a variety of techniques to support this concept. On the other hand, a large number of quenched-in nuclei could lead to a high nucleation rate and slow growth. Inoue (2000) prescribed that such nanocrystallisation in $\mathrm{Zr}$ alloys is promoted by the addition of elements such as $\mathrm{Au}, \mathrm{Ag}, \mathrm{Pd}$ and $\mathrm{Pt}$. These have strong interactions with $\mathrm{Zr}$ and could lead to clustering in the glass and consequent nanocrystallisation. Kelton (1998) has proposed a third model based on linked fluxes of interface attachment and diffusion in the glass to account for these observations.

A comparison between crystallisation of rapidly solidified thin ribbons and slowly cooled bulk glassy Fe40-Ni40-P14-B6 (Tiwari et al 1987; Shen \& Schwarz 2001) is of interest. Table 2 compares the various parameters incidental to crystallisation. It is seen that that the extent of supercooled region as defined by the difference between $T_{x}$ and $T_{g}$ increases by $42 \mathrm{~K}$, leading to improved glass formation in the solid state. Bulk glasses crystallise by homogeneous nucleation followed by growth at a constant rate. The nucleation rate in the bulk glass is four orders of magnitude lower than in rapidly quenched samples, indicating that the ribbons may have had heterogeneous impurities. It is also noteworthy that the size of the crystals in the two cases differs by an order of magnitude. Figure 6 shows a partially crystallised state in the thin ribbon.

\section{Link with icosahedral order}

Koester et al (1996) were the first to report formation of quasicrystals on devitrification of a quaternary Zr-based bulk metallic glass. This is an important contribution as it hinted at a link between quasicrystals and BMGs. Nanoquasicrystallisation has been observed in $\mathrm{Zr}-\mathrm{Ti}-\mathrm{Ni}$, $\mathrm{Zr}-\mathrm{Al}-\mathrm{Cu}-\mathrm{Ni}-\mathrm{Ag}, \mathrm{Zr}-\mathrm{Al}-\mathrm{Cu}-\mathrm{Ni}-\mathrm{Pd}$ (Inoue et al 1999) and various other hafnium-containing 
Table 2. Comparison of crystallisation parameters of ribbons and bulk glassy $\mathrm{Fe}_{40} \mathrm{Ni}_{40} \mathrm{P}_{14} \mathrm{~B}_{6}$.

\begin{tabular}{lcc}
\hline Parameter & Melt spun $^{a}$ & Bulk metallic glass $^{b}$ \\
\hline Cooling rate $(\mathrm{K} / \mathrm{s})$ & $10^{5}-10^{6}$ & $10^{2}-10^{3}$ \\
Shape & Ribbons & Spheres \\
Thickness & $50 \mu \mathrm{m}$ & $2 \mathrm{~mm}$ \\
$T_{g}\left({ }^{\circ} \mathrm{C}\right)$ & 387 & 367 \\
$T_{x}\left({ }^{\circ} \mathrm{C}\right)$ & 393 & 409 \\
Avrami exponent & $3 \cdot 96$ & 4.05 \\
Nucleation rate $\left(\right.$ nuclei $\left./ \mathrm{m}^{3} \mathrm{~s}\right)$ & $\sim 10^{15}$ & $\sim 10^{11}$ \\
Growth rate $(\mathrm{m} / \mathrm{s})$ & $\sim 10^{-9}$ & $\sim 10^{-7}$ \\
Microstructural scale $(\mu \mathrm{m})$ & $\sim 3$ & $\sim 30$
\end{tabular}

References: ${ }^{a}$ Ranganathan \& Von Heimendahl (1981); Tiwari et al (1981) ${ }^{b}$ Shen \& Schwarz (2001)

alloys. In most of the alloys the quasicrystals so precipitated are metastable. $\mathrm{Zr}-\mathrm{Ti}-\mathrm{Ni}$ is an interesting system to study because it forms nanoquasicrystal over a wide composition range and they are stable upto 4 hours of annealing at the peak temperature of the crystallisation reaction. A bright field image and nano beam electron diffraction patterns of this quasicrystalline phase corresponding to 5-fold, 3-fold and 2-fold axis is given in figure 7. It is believed that oxygen distribution in the amorphous alloy has a large influence on the crystallisation and quasicrystallisation behaviour of the alloy. 3D atom probe microscopic study by Murty et al (2000) has shown that impurity oxygen atoms segregate in the crystalline phase during the process of crystallisation.

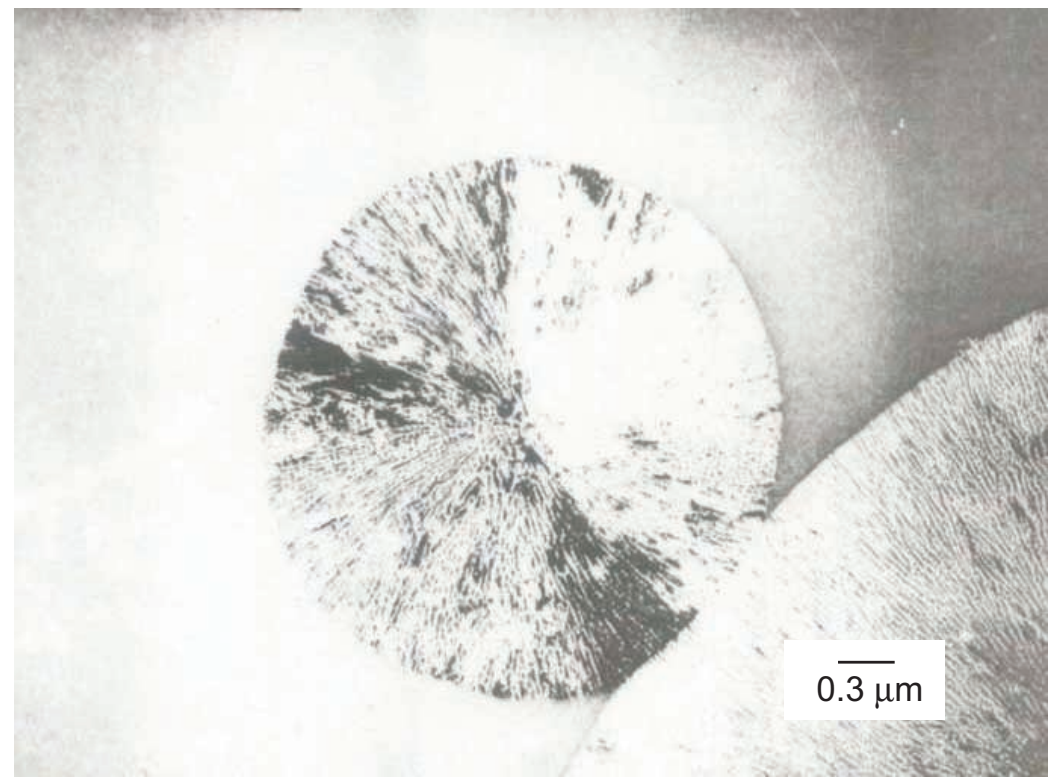

Figure 6. TEM micrograph of a partially crystallised state of an iron based metallic glass. 

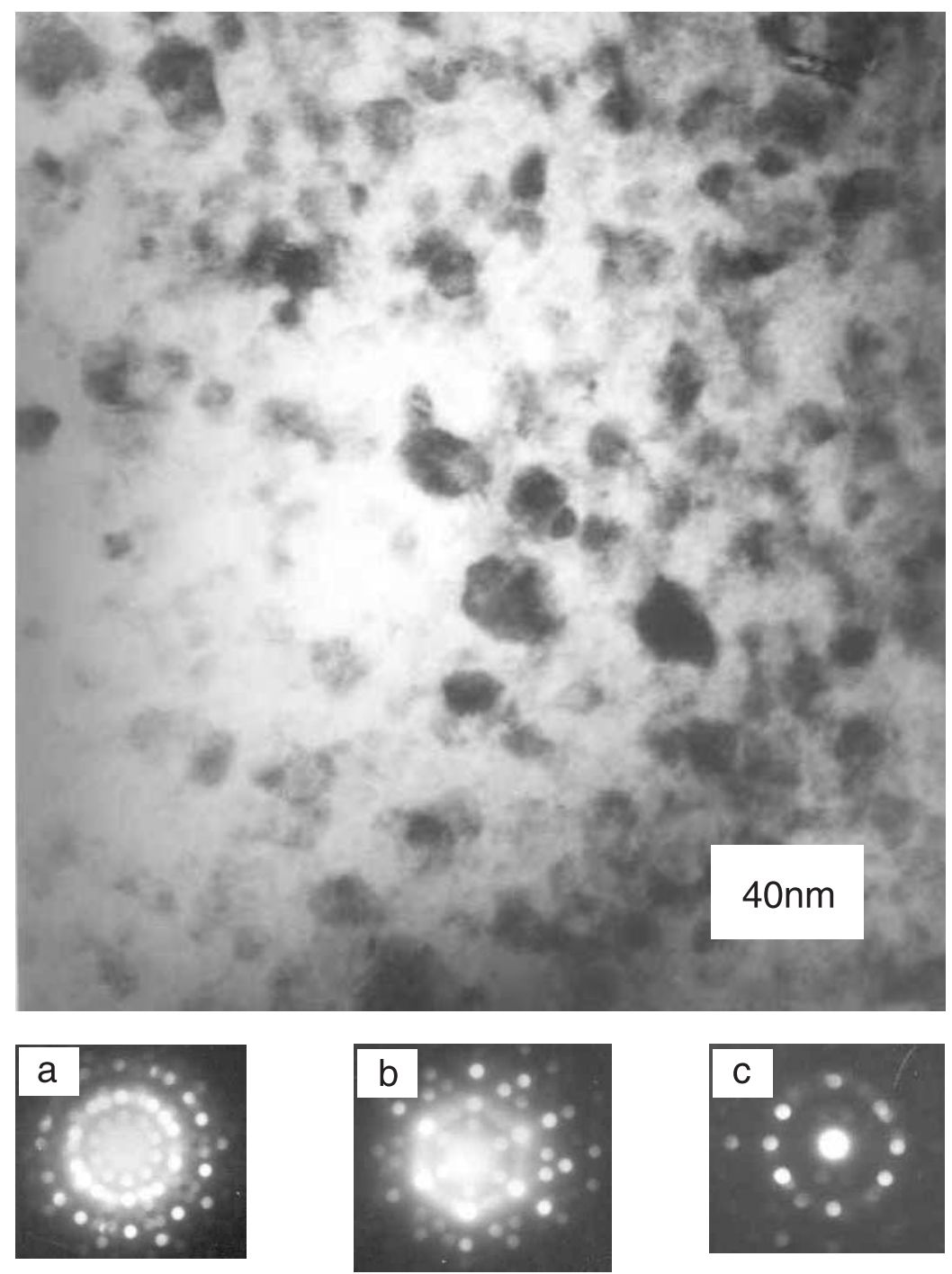

Figure 7. Bright field electron micrograph of nanoquasicrystallised $\mathrm{Zr}-\mathrm{Ti}-\mathrm{Ni}$ alloy along with nano beam electron diffraction patterns showing (a) 5-fold (b) 3-fold (c) 2-fold symmetry.

In a study of hafnium-based glasses Li et al (2001) have shown that the icosahedral cluster in the amorphous matrix is stabilised by the highly negative heat of mixing among the constituent elements and the atomic size difference between the constituent elements. In many cases the crystalline phases that precipitate instead of the quasicrystalline phases are related to the quasicrystalline phase by having icosahedral clusters (Louzguine et al 2001). From the geometrical standpoint in an icosahedral cluster the difference in size between the atom at the centre and that at the corners should be more than 5\%. That is achieved in multinary glassforming alloy systems. This type of geometrical clusters act as seeds of quasicrystals at the initial stages of crystallisation. 


\section{Properties}

The difference in the densities between the as-cast amorphous and fully crystallized states is around $0.5 \%$, which is much smaller than the previously reported value range of about $2 \%$ for the glasses with much higher $R c$ above $10^{5} \mathrm{~K} / \mathrm{s}$. Such small differences in values indicate that bulk amorphous alloys have higher density randomly packed atomic configurations. Although the difference in densities between the amorphous and crystalline phases is small, the density increases in a systematic fashion on annealing to structurally relaxed glass and ultimately the crystals.

The stability of the supercooled liquid offers an unusual opportunity to study the temperature dependence of viscosity. The melt-spun glasses provided a limited possibility. The study of BMGs by Johnson (1999) showed that viscosity over fifteen orders of magnitude fit very well with the Vogel-Fulcher equation,

$$
\eta=\eta_{0} \cdot \exp \left(D T_{o} / T-T_{o}\right) .
$$

The parameter $D$ is called the fragility index and $T_{o}$ is the Vogel-Fulcher temperature. Angell (1995) has distinguished between fragile and strong glasses based on the dependence of viscosity on $T / T g$. Silica, silicates and some organic polymers are strong glasses, whereas most metallic glasses are fragile. The fragility index $D$ has a value of about 2 for most fragile liquids and about 100 for silicate glass, classified as a strong glass. For strong BMGs, $D$ varies from 20 to 25 . Above $T_{g}$, a strong liquid has viscosity many orders of magnitude more than that of fragile glass. This high viscosity retards crystal nucleation. Strong glasses are naturally resistant to crystallisation. Energetically these glasses are close to crystals. In the energy landscape picture for glass transition they exhibit a strong megabasin.

The mechanical behaviour of bulk metallic glasses offers several interesting possibilities. It can be studied in the as-cast state, in the supercooled liquid region, after partial or full devitrification into bulk nanocrystals and quasicrystals. In the fully amorphous alloy, fracture takes place along the maximum shear plane at $45^{\circ}$ to the tensile axis and shows a welldeveloped vein pattern. If the alloy is deformed in the supercoooled region, Newtonian flow occurs with attendant high strain rate superplasticity. In the case of nanocrystallized alloys it was found that the tensile fracture strength, Vickers hardness and Young's modulus increased as a function of the volume fraction of the $\mathrm{Zr}_{2} \mathrm{CuPd}$ phase in $\mathrm{Zr}-\mathrm{Al}-\mathrm{Cu}-\mathrm{Pd}$ alloys. The increases were of the order of $20 \%$ over the fully amorphous alloy. However, this behaviour was observed only when there was some residual glass left as a matrix. It is possible to correlate this with the fracture mode. With increasing volume fraction of nanocrystals a distinct change occurs in the mode of fracture.

Bulk metallic glasses have very high yield strength and very high elastic limit. The Hookean elastic strain that a metallic glass can support in tension or in bending is almost double that of a commercially available crystalline material. Metallic glasses are premier spring material. They have very high fracture strength coupled with $2-3 \%$ of elastic strain. Conventional aluminium, titanium alloys and steels can sustain 1-2\% of elastic strain. A large domain of high fracture strength and elastic strain can be achieved by nanoquasicrystallisation, nanocrystallisation and by reinforcing ceramic particles into the amorphous matrix. Metallic glasses are relatively weak in shear so they have a comparatively high Poisson's ratio which varies between 0.35 and $0 \cdot 37$. Upon yielding, a metallic glass tends to form a localised shear band that traverses the sample. In the plastic region, serrated flow is observed. This flow behaviour is very different from that of normal crystalline materials in the sense that there is a sudden load drop associated with the movement of a shear band. This sudden load drop is not observed in normal 
crystalline materials. Despite the tendency to form a localised shear band, a metallic glass has reasonably high plain strain fracture toughness, which indicates that it has a considerable amount of plastic zone which can screen a crack tip. The effect of crystallinity on the fracture toughness of lanthanum-based bulk amorphous alloys has been studied by Nagendra et al (2000). The introduction of crystallinity results in the reduction of impact toughness of the alloy. Observation of fracture surface reveals that with the introduction of crystalline phases, the fracture type changes from ductile vein type fracture to brittle intergranular cleavage type fracture. Embrittlement can also be introduced into bulk metallic glasses by low temperature annealing (Ramamurty et al 2002). A huge loss in impact toughness has been observed after annealing La-based bulk metallic glass at and near $T_{g}$. This loss in toughness has been attributed to the decrease in free volume and increase in viscosity of the glass due to the annealing process.

Deformation-induced nanocrystallisation in bulk amorphous alloys is of recent interest. Deformation behaviour of this kind of materials is highly localised in nature and they do not show strain hardening. During localised deformation formation of shear bands, strain softening and adiabatic heating is observed. Nanocrystallisation in a $\mathrm{Zr}-\mathrm{Ti}-\mathrm{Cu}-\mathrm{Ni}-\mathrm{Al}$ bulk metallic glass has been observed during nanoindentation experiments (Kim et al 2002). Nano particles of $\mathrm{Zr}_{2} \mathrm{Ni}$ has been observed at the indentation tip and at the sides of the indentation where the state of stress is highest following which discontinuous shear bands form around it. This crystallisation phenomenon is attributed to the enhanced atomic mobility under the condition of high stress.

In some cases partial crystallisation leads to the enhancement of properties. Inoue et al (2000) indicated that the control of microstructure is very important as the optimum property design is related to the microstructure. It is clear that the control of microstructure involves controlling a few parameters, those are precipitated phase, its shape, size, volume fraction and interface structure.

Szuecs et al (2001) have studied the mechanical properties of ductile phase-reinforced bulk metallic glass composites in the $\mathrm{Zr}-\mathrm{Ti}-\mathrm{Nb}-\mathrm{Cu}-\mathrm{Ni}-\mathrm{Be}$ system. In this study, an increase in compressive strength and strain to failure has been observed. It is concluded that the reinforcements stop the shear bands from propagating freely which results in improvement in the mechanical property.

Bulk metallic glasses have a number of attractive properties, which may find applications in various technical fields. The processability of bulk metallic glasses is very good. Below the crystallisation temperature, they deform by viscous flow making them suitable for near net shape forming processes. This means significant economic and environmental advantages in the mass production of precision components as machining processes and associated waste products can be avoided. Indeed it is possible to use manufacturing techniques akin to those used in polymer products.

\section{Chemical properties}

The high corrosion resistance of metallic glasses is contrary to expectation, as they are in a higher energy state. The absence of defects and their chemical homogeneity confer on them high corrosion resistance. The composition of the glass plays an important role. $\mathrm{Cr}$, Mo and $\mathrm{P}$ can enhance corrosion resistance as has been revealed in many early studies on meltspun ribbons (Raja et al 1988). It is even more critical to study the corrrosion resistance of BMGs as they offer possible use as structural materials. Effect of chemical composition and environment has been studied by Inoue (2000). Nb- and Ta-containing amorphous alloys show 
very good corrosion resistance in $\mathrm{HCl}$ and $\mathrm{NaCl}$ solutions. The effect of additional elements on the corrosion resistance is largest for $\mathrm{Nb}$ followed by $\mathrm{Ta}, \mathrm{Ti}$ and $\mathrm{Cr}$. Addition of alloying elements not only increases corrosion resistance but also adds to the GFA of the alloy. Pang et al (2002) have noted the beneficial effects of $\mathrm{Cr}$, Mo and $\mathrm{P}$ in ferrous BMGs. Corrosion resistance of $\mathrm{Zr}-\mathrm{Ti}-\mathrm{Cu}-\mathrm{Ni}-\mathrm{Be}$ amorphous alloy is not very different in comparison to its crystalline counterpart in $\mathrm{NaCl}$ and $\mathrm{NaClO}_{4}$ solutions.

\section{Applications}

Bulk metallic glasses possess a number of very attractive properties and in many cases these properties are enhanced by suitable heat treatment. Bulk metallic glasses possess an unique combination of strength and toughness. The ability of this material to store a high amount of elastic energy has made it a potential spring material. This desirable combination of properties has led to its first and most visible use in the heads of golf clubs. Considerable amount of ductility can be imparted into the material by the addition of ceramic second phase particles. This composite can be used as armour penetrator material. It is possible to envisage structural materials for use in aircraft frames, automobiles and medical implants. These materials have large supercooled liquid regions in which the workability of the material is very high. This property has been exploited in friction welding of Pd-based bulk metallic glasses (Kawamura \& Ohno 2001). After friction welding, no crystallisation at the welded interface is observed and the strength of the interface is almost comparable with that of metallic glass. This overview has promoted BMGs as prime structural materials. The magnetic properties of BMGs and nanocomposites produced from them by devitrification promise new applications as well, which have not been covered here. The high strength, hardness, fracture toughness and fatigue strength of bulk metallic glasses make them ideal for use as optical, die, tool and cutting materials. It is clear that we are at the start of the new era as the use of BMGs as engineering materials expands in scope.

Stimulating discussion with Prof S Ramaseshan, Prof K Chattopadhyay, Prof Vikram Jayaram and Dr U Ramamurty during the course of this work is acknowledged. The scientific collaboration with Prof A Inoue, Tohoku University, Sendai, Japan has been of immense value and the hospitality of the Tohoku University in the form of a visiting Professorship to one of the authors (SR) is gratefully acknowledged.

\section{References}

Amiya K, Inoue A 2000 Thermal stability and mechanical properties of $\mathrm{Mg}-\mathrm{Y}-\mathrm{Cu}-\mathrm{M}(\mathrm{M}=\mathrm{Pd}, \mathrm{Ag})$ bulk amorphous alloys Mater. Trans. Japan Inst. Metals 41: 1460-1462

Anantharaman T R (ed.) 1984 Metallic glasses: Production, properties and applications (Trans. Tech. Publications)

Angell C A 1995 Formation of glasses from liquids and biopolymers. Science 267: 1924-1935

Banerjee S, Savalia R T, Dey G K 2001 Glass formation and crystallisation in rapidly solidified zirconium alloys. Mater. Sci. Eng. A304-306: 26-33

Busch R, Schneider S, Peker A, Johnson W L 1995 Decomposition and primary crystallisation in undercooled Zr-Ti-Cu-Ni-Be melts. Appl. Phys. Lett. 67: 1544-1546 
Chattopadhyay K, Ramachandrarao P, Lele S, Anantharaman T R 1976 Crystal structure of a metastable aluminium-nickel phase obtained by splat cooling. Proc. 2nd Int. Conf. on Rapidly Quenched Metals (Cambridge, MA: MIT Press) p. 157

Chen H S, Turnbull D 1967 Thermal evidence of a glass transition in gold-silicon-germanium alloy. Appl. Phys. Lett. 10: 284-286

Conner R D, Dandliker R B, Johnson W L 1998 Mechanical properties of tungsten and steel fiber reinforced $\mathrm{Zr}_{41.5} \mathrm{Ti}_{13 \cdot 75} \mathrm{Cu}_{12.5} \mathrm{Ni}_{10} \mathrm{Be}_{22.5}$ metallic glass matrix composites. Acta Mater. 46: 60896102

Drehman A J, Greer A L, Turnbull D 1982 Bulk formation of metallic glass: $\mathrm{Pd}_{40} \mathrm{Ni}_{40} \mathrm{P}_{20}$. Appl. Phys. Lett. 41: 716-717

Egami T 2002 Nano-glass mechanism of bulk metallic glass formation. Mater. Trans. Jpn. Inst. Met. 43: $510-517$

Egami T, Greer A L, Inoue A, Ranganathan S (eds) 2003 Supercooled liquids, the glass transition and bulk metallic glasses (Warrendale, PA: Mater. Res. Soc.)

He Y, Poon J, Shiflet G J 1988 Synthesis and properties of metallic glasses that contain aluminum. Science 41: 1640-1642

Herold U, Koster U 1978 The influence of metal or metalloid exchange on crystallisation of amorphous Fe-B alloys. Rapidly quenched metals III (ed.) B Cantor (London: Metals Society) vol.1, p. 281

Inoue A 1995 High strength bulk amorphousalloys with low critical cling rates (overview). Mater. Trans. Jpn. Inst. Met. 36: 866-875

Inoue A 1998 Bulk Amorphous alloys - Preparation and fundamental characteristics (Trans. Tech. Publications)

Inoue A 1999 Bulk amorphous alloys - Practical characteristics and applications (Trans. Tech. Publications)

Inoue A 2000 Stabilization of metallic supercooled liquid and bulk amorphous alloys. Acta Mater. 48: 279-306

Inoue A, Ohtera K, Tsai A P, Masumoto T 1988 New amorphous alloys with good ductility in Al-Y-M and Al-La-M (M = Fe, Co, Ni or Cu) systems. Jpn. J. Appl. Phys. 27: L280-L282

Inoue A, Zhang T, Masumoto T 1989 Al-La-Ni amorphous alloys with a wide supercooled liquid region. Mater. Trans. Jpn. Inst. Met. 12: 965-972

Inoue A, Zhang T, Masumoto T $1990 \mathrm{Zr}-\mathrm{Al}-\mathrm{Ni}$ amorphous alloys with high glass transition temperature and significant supercooled liquid region. Mater. Trans. Jpn. Inst. Met. 31: 177-183

Inoue A, Nakamura T, Nishiyama N, Masumoto T $1992 \mathrm{Mg}-\mathrm{Cu}-\mathrm{Y}$ bulk amorphous alloys with high tensile strength produced by high pressure die casting method. Mater. Trans. Jpn. Inst. Met. 33: 937-945

Inoue A, Nakamura T, Sugita T, Zhang T, Masumoto T 1993 Bulky La-Al-TM (TM = transition metal) amorphous alloys with high tensile strength produced by high pressure die casting method. Mater. Trans. Jpn. Inst. Met. 34: 351-358

Inoue A, Shinohara Y, Gook J S 1995 Thermal and magnetic properties of bulk Fe-based glassy alloys prepared by copper mold casting. Mater. Trans. Jpn. Inst. Met. 36:1427-1433

Inoue A, Nishiyama N, Matsuda T 1996 Preparation of bulk glassy $\mathrm{Pd}_{40} \mathrm{Ni}_{10} \mathrm{Cu}_{30} \mathrm{P}_{20}$ alloy of $40 \mathrm{~mm}$ diameter by water-quenching. Mater. Trans. Jpn. Inst. Met. 37: 181-184

Inoue A, Nishiyama N, Kimura H 1997 Preperation and thermal stability of bulk amorphous $\mathrm{Pd}_{40} \mathrm{Cu}_{30} \mathrm{Ni}_{10} \mathrm{P}_{20}$ alloy cylinder of $72 \mathrm{~mm}$ diameter. Mater. Trans. Jpn. Inst. Met. 38: 179-183

Inoue A, Zhang T, Saida J, Matsushita M, Chen M W, Sakurai T 1999 Formation of icosahedral quasicrystalline phase in $\mathrm{Zr}-\mathrm{Al}-\mathrm{Ni}-\mathrm{Cu}-\mathrm{M}(\mathrm{M}=\mathrm{Pd}, \mathrm{Pt}, \mathrm{Au}, \mathrm{Ag})$ systems. Mater. Trans. Jpn. Inst. Met. 40: 1181-1184

Inoue A, Fan C, Saida J, Zhang T 2000 High-strength Zr-based bulk amorphous alloys containing nanocrystalline and nanoquasicrystalline particles. Sci. Technol. Adv. Mater. 1: 73-86

Inoue A, Yavari A R, Johnson W L, Dauskardt R H 2001 Supercooled liquid, bulk glassy and nanocrystalline states of alloy (Warrendale, PA: Mater. Res. Soc.)

Johnson W L 1999 Bulk glass-forming metallic alloys: Science and technology. MRS Bull. 24: 42-56 
Johnson W L 2002 Bulk amorphous alloys-an emerging engineering material. J. Mater. 54: 40-43 Johnson W L, Inoue A, Liu C T (eds) 1999 Bulk metallic glasses (Warrendale, PA: Mater. Res. Soc.) Kawamura Y, Ohno Y 2001 Superplastic bonding of bulk metallic glasses using friction. Scr. Mater. 45: 279-285

Kelton K F 1998 A new model for nucleation in bulk metallic glasses. Philos. Mag. Lett. 77: 337-343

Kim J J, Choi Y, Suresh S, Argon A S 2002 Nanocrystallisation during nanoindentation of a bulk amorphous metal alloy at room temperature. Science 295: 654-657

Klement W, Willens R H, Duwez P 1960 Non-crystalline structure in solidified gold-silicon alloys. Nature (London) 187: 869-870

Koester U, Meinhardt J, Ros S, Liebertz H 1996 Formation of quasicrystals in bulk glass-forming $\mathrm{Zr}-\mathrm{Cu}-\mathrm{Ni}-\mathrm{Al}$ alloys. Appl. Phys. Lett. 69: 179-181

Kui H W, Greer A L, Turnbull D 1984 Formation of bulk metallic glass by fluxing. Appl. Phys. Lett. 45: 615-616

Li C, Ranganathan S, Inoue A 2001 Initial crystallisation processes of $\mathrm{Hf}-\mathrm{Cu}-\mathrm{M}(\mathrm{M}=\mathrm{Pd}, \mathrm{Pt}, \mathrm{Ag})$ amorphous alloys. Acta Mater. 49: 1903-1908

Loffler J F, Johnson W L, Wagner W, Thiyagarajan P 2000 Comparison of the decomposition and crystallisation behaviour of $\mathrm{Zr}$ and $\mathrm{Pd}$ based bulk amorphous alloys. Mater. Sci. Forum 343-346: $179-184$

Louzguine D V, Ko M S, Ranganathan S, Inoue A 2001 Nanocrystallisation of the $\mathrm{Fd} \overline{3} \mathrm{~m} \mathrm{Ti}_{2} \mathrm{Ni}$ type phase in Hf-based metallic glasses. J. Nanosci. Nanotechnol. 1: 185-190

Madge S V 1999 Mechanical alloying of Zr-based bulk metallic glass-forming alloys. Master of Engineering Thesis, Indian Institute of Science, Bangalore

Murty B S, Ranganathan S 1998 Novel materials synthesis by mechanical alloying/milling. Int. Mater. Rev. 43: 1-60

Murty B S, Ping D H, Hono K, Inoue A 2000 Influence of oxygen on the crystallisation behaviour of $\mathrm{Zr}_{65} \mathrm{Cu}_{27 \cdot 5} \mathrm{Al}_{7 \cdot 5}$ and $\mathrm{Zr}_{66 \cdot 7} \mathrm{Cu}_{33 \cdot 3}$ metallic glasses. Acta Mater. 48: 3985-3996

Nagendra N, Ramamurty U, Goh T T, Li Y 2000 Effect of crystallinity on the impact toughness of a La-based bulk metallic glass. Acta Mater. 48: 2603-2615

Nishiyama N, Inoue A 2002 Glass-forming ability of $\mathrm{Pd}_{42 \cdot 5} \mathrm{Cu}_{30} \mathrm{Ni}_{7 \cdot 5} \mathrm{P}_{20}$ alloy with a low critical cooling rate of $0.067 \mathrm{Ks}^{-1}$. Appl. Phys. Lett. 80: 568-570

Pang S J, Zhang T, Asami K, Inoue A 2002 Synthesis of Fe-Cr-Mo-C-B-P bulk metallic glasses with high corrosion resistance. Acta Mater. 50: 489-497

Peker A, Johnson W L 1993 A highly processable metallic glass: $\mathrm{Zr}_{41 \cdot 2} \mathrm{Ti}_{13 \cdot 8} \mathrm{Cu}_{12 \cdot 5} \mathrm{Ni}_{10} \mathrm{Be}_{22 \cdot 5} \mathrm{Appl}$. Phys. Lett. 63: 2342-2344

Perepezko J H, Hebert R J 2002 Amorphous aluminium alloys-Synthesis and stability. J. Mater. 54: 34-39

Pettifor D G 1988 Structure maps in magnetic alloy design. Physica B149: 3-10

Raja V S, Kishore, Ranganathan S 1988 Effect of molybdenum and silicon on the electrochemical corrosion behaviour of FeNiB metallic glass. Corrosion 44: 263-270

Ramachandra Rao P 1980 On glass formation in metal-metal systems. Z Metallk. 71: 172-177

Ramachandra Rao P, Scott M G, Chadwick G A 1972 Constitution and microstructure of Rapidly solidified aluminium-germanium alloys. Philos. Mag. 25: 961-982

Ramamurty U, Lee M L, Basu J, Li Y 2002 Embrittlement of a bulk metallic glass due to low temperature annealing. Scr. Mater. 47: 107-111

Ranganathan S. Heimendahl M V 1981 The three activation energies with isothermal transformations: Application to metallic glasses. J. Mater. Sci. 16: 2401-2404

Sastry G V S, Suryanarayana C, Srivastava O N, Davies H A 1978 Crystallization of an amorphous Al-Pd alloy. Trans. Indian Inst. Met. 31: 292-293

Shechtman D, Blech I, Gratias D, Cahn J W 1984 Metallic phase with long range orientational order and no translational symmetry. Phys. Rev. Lett. 53: 183-185

Shen T D, Schwarz R B 2001 Bulk ferromagnetic glasses in the Fe-Ni-P-B system. Acta Mater. 49: $837-847$ 
Szuecs F, Kim C P, Johnson W L 2001 Mechanical properties of Zr-Ti-Nb-Cu-Ni-Be ductile phase reinforced metallic glass composite. Acta Mater. 49: 1507-1513

Tiwari R S, Heimendahl M V, Ranganathan S 1987 On the variation of interlamellar spacing in the crystallisation product of the amorphous alloy $\mathrm{Fe}_{40} \mathrm{Ni}_{40} \mathrm{P}_{14} \mathrm{~B}_{6}$. Z. Metallkde. 78: 275-279

Turnbull D 1969 Under what conditions can a glass be formed? Contemp. Phys. 10: 473-488 